
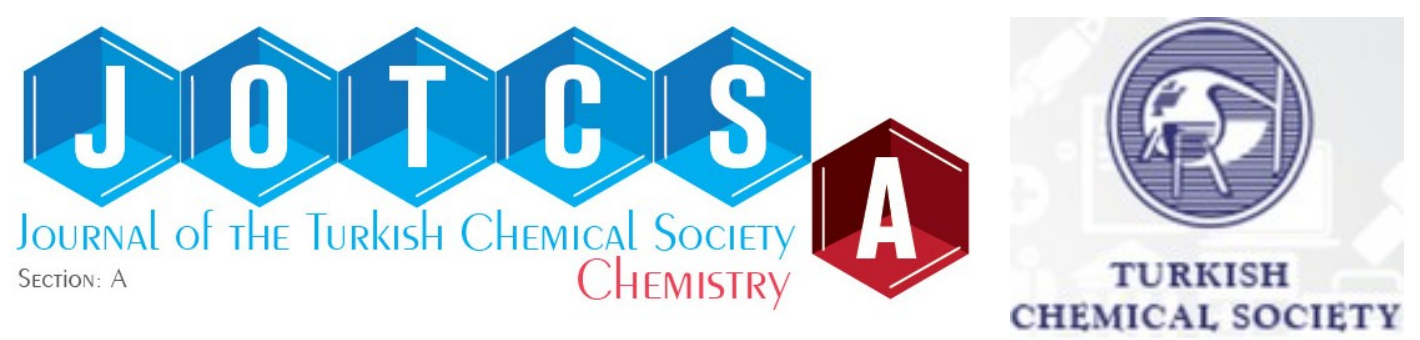

\title{
Investigation of Photochromic Fluorescence Features and Synthesis of Diarylethene Type Naphthalimide Compounds
}

\author{
Ersin Orhan $^{1 *}$ (D) and Mustafa Narin ${ }^{1}$ \\ ${ }^{1}$ Department of Chemistry, Faculty of Arts and Science, Düzce University, 81620 Düzce, Turkey.
}

\begin{abstract}
The aim of the study was to synthesise novel photo-exchangeable photochromic fluorescent compounds. 3,4-Bis(3,5-dimethyl-4-pyrazolyl)-N-butyl-1,8-naphthalimide $\mathbf{6}$ and 3,4-bis (1,3,5trimethyl-4-pyrazolyl)-N-butyl-1,8-naphthalimide 7 naphthalimide derivative new compounds were prepared via two-step Suzuki coupling reaction of pyrazolylboronic acid esters from N-butyl-4-bromo3-iodo-1,8-naphthalimide and characterized by ${ }^{1} \mathrm{H}-\mathrm{NMR},{ }^{13} \mathrm{C}-\mathrm{NMR}, \mathrm{MS}$ and FTIR. Their photochromic fluorescence properties were investigated. Additionally, a solvent effect on the fluorescent properties of $\mathbf{6}$ and $\mathbf{7}$ was investigated. Increase of organic solvent polarity results in a red shift (to longer wavelengths) of the fluorescence emissions.
\end{abstract}

Keywords: Solvent effect, Naphthalimide, Diarylethene, Fluorescent switch, Photochromism.

Submitted: September 19, 2019. Accepted: November 01, 2019.

Cite this: Orhan $E$, Narin $M$. Investigation of photochromic fluorescence features and synthesis of diarylethene type naphthalimide compounds. JOTCSA. 2019; 7(1): 97-106.

DOI: https://doi.org/10.18596/jotcsa.622256.

Corresponding Author. E-mail: ersinorhan@duzce.edu.tr

\section{INTRODUCTION}

Photochromic compounds can be divided into several groups according to their type of photoreaction. The most studied photochromic series are fulgides, spiropyranes and diarylethenes. Among these, diarylethenes are the most promising compounds for many industrial applications due to their fatigue resistance and superior thermal stability.

There are many studies on the synthesis and photochromic properties of non-fluorescence photochromic diarylenes in different environments. Photochromic fluorescent diarylethenes have attracted attention in the development and use of possible opticalelectronic devices in recent years as molecular switches and optical memory systems (1-6).
Photochromic fluorescent diarylethenes must have many important features for industrial application such as fatigue resistance, thermal stability, high quantum yields (for both photochromic and fluorescence behaviour), and so on.

It is difficult to synthesise excellent photochromic fluorescent compounds with all the necessary properties for industrial applications. It is almost impossible to predict the detailed photochromic and also fluorescent properties of the compounds before synthesising. It is important to synthesise new photochromic compounds that may exhibit this fluorescence.

On the other hand, research on photochromic fluorescent diarylethenes is limited. Photochromic fluorescent diarylethenes must meet many important criteria in order to find an application. These criteria can be listed as 
follows: Criteria for photochromic properties: quantum data on ring opening and closing reactions, the repeatability of ring opening and ring closing reactions of the molecular structure over time without degradation, this is called resistance to fatigue. Thermal stability of the open and closed forms should not be degraded at normal temperatures and so on. In addition, there are criteria for the fluorescent properties of the molecules of interest (7-13).

In the criteria related to fluorescent properties, undoubtedly one of the most important features is high fluorescent quantum yields. In photochromic fluorescent molecules, the fluorescent properties of both the open form and closed forms are measured, and in some cases it is known that the open form exhibits more fluorescence and in some cases the closed form exhibits stronger fluorescence. What is important here is that there is a significant difference in fluorescent property between the ring-open or closed form of the photochromic molecule.

One of the important points of both the photochromic and fluorescent properties mentioned above is the absorption bands of the open form and the closed form. Open forms are more sensitive to UV light in photochromic compounds, while closed forms (usually coloured) are sensitive to light in the visible region. It is also important that the maximum wavelength difference between open forms and closed forms is large. Similarly, in terms of fluorescent properties, the absorption wavelength and emission wavelength values of the molecule are important for many applications. In short, it is difficult to synthesise photochromic fluorescent diarylethenes with ideal properties and it is often not possible to predict all of the aforementioned properties. In this respect, it is important to synthesise different photochromic compounds that may exhibit fluorescence (14-23).

For this reason, in this study we aimed to synthesize a diethylether-like photochromic fluorescent molecule which has a novel pyrazole structure based on bisaryl naphthalimide.

\section{EXPERIMENTAL}

\section{Material and Methods \\ Materials}

4-Bromo-1,8-naphthalic anhydride, 3,5dimethyl-4-pyrazole-4-boronic acid pinacol ester, 1,3,5-trimethyl-4-pyrazole-4-boronic acid pinacol ester and other starting chemical compounds were purchased from the company Merck, Sigma-Aldrich, Acros Organics and ABCR. 4-bromo-N-butyl-3-iodo-1,8-naphthalimide was prepared according to the procedures in the literature (24).

\section{Methods}

Some parts of solvent were of analytical grade and purified by distillation before use. Other reagents were used as received without further purification. Some part of studies of naphthalimide derivatives were performed under argon using standard schlenk techniques and dry solvents. All chemicals were purchased from Merck, Acros Organics, ABCR and Aldich Chemical Company. ${ }^{1} \mathrm{H}$ and ${ }^{13} \mathrm{C}$ NMR spectra were recorded on Bruker $400 \mathrm{MHz}$ spectrometers for samples in $\mathrm{CDCl}_{3}$. The signals are expressed as parts per million down fields from tetramethylsilane, used as an internal standard ( $\delta$ value). Splitting patterns are indicated as $s_{\text {, }}$ singlet; $d$, doublet; $t$, triplet; $q$, quartet; $m$, multiplet. Mass spectra were taken with an $A B$ Sciex 4000 QTRAP LC-MS/MS. FT-IR spectra were measured using a SHIMADZU FT-IR spectrometer. Luminescence spectra were measured on a SHIMADZU RF-5301PC fluorescent spectrophotometer. UV-Vis spectra were recorded on a T80+ UV-Vis spectrophotometer. Photochemical reactions in organic solvents were carried out in a $10 \mathrm{~mm}$ path length quartz cell using an $8 \mathrm{~W}$ Three-Way UV lamp (Cole-Parmer) (for $365 \mathrm{~nm}$ ) and an Obelux CR9 Forensic Lights Green (for 530 nm). During the photoreaction, solutions in the cell were stirred. Melting points were measured in open capillary tubes with Thermo Scientific 9200 melting point apparatus and are not corrected. Solvents were dried over anhydrous sodium sulphate. Flash column chromatographic separation was carried out on Merck Kieselgel 60 (230-400 mesh) using ethyl acetate and nhexane as the eluent. Analytical thin-layer chromatography was performed on Merck precoated silica gel $60 \mathrm{~F}-254,0.25-\mathrm{mm}$ thick TLC plates.

\section{Synthesis}

3-(3,5-Dimethyl-4-pyrazolyl)-4-bromo-N-butyl1,8-naphthalimide (4)

Naphthalimide derivative (1) (0.2 g, 0.43 mmol), 3,5-dimethyl-4-pyrazoleboronic acid pinacol ester $(0.59 \mathrm{~g}, 4.3 \mathrm{mmol})$, tetrakis(triphenylphosphine)palladium(0) (0.25 $\mathrm{g}, 1.29 \mathrm{mmol})$, potassium carbonate $(0.049 \mathrm{~g}$, $0.043 \mathrm{mmol})$, catalyst ratio of tris(dibenzylideneacetone)dipalladium(0), THF $(30 \mathrm{~mL})$, aqueous $(10 \mathrm{~mL})$ stirred for 5 hours at room temperature. No photochromicity was observed when TLC was checked. Boiling at 65 ${ }^{\circ} \mathrm{C}$ for 3 hours, the reaction was found to complete by TLC control. $10 \%$ sodium bicarbonate solution was added. The organic fraction was dried with sodium sulphate. The organic fraction was then evaporated. The 
residual raw product was purified via column chromatography over ethyl acetate-n-hexane (5-20\%). ${ }^{1} \mathrm{H}$ NMR analysis showed that 1 mole was attached. 4 Light coloured brown solid 0.09 g, 50\%, m.p.: $141-144{ }^{\circ} \mathrm{C} .{ }^{1} \mathrm{H}$ NMR $(400 \mathrm{MHz}$, $\left.\mathrm{CDCl}_{3}, \mathrm{ppm}\right): \delta 0.83\left(\mathrm{t}, 3 \mathrm{H},-\mathrm{CH}_{2} \mathbf{C H}_{3}\right), 1.30-$ $1.40\left(\mathrm{~m}, 2 \mathrm{H},-\mathbf{C H}_{2} \mathrm{CH}_{3}\right), 1.57-1.63(\mathrm{~m}, 2 \mathrm{H}$, $\left.\mathrm{NCH}_{2} \mathbf{C H}_{2}-\right), 1.98\left(\mathrm{~s}, 3 \mathrm{H},-\mathrm{CH}_{3}\right.$, pyrazole), 2.10 ( $\mathrm{s}, 3 \mathrm{H},-\mathrm{CH}_{3}$, pyrazole), $4.10\left(\mathrm{t}, 2 \mathrm{H},-\mathrm{NCH}_{2}-\right)$, 7.02-8.80 (m, 4H, Ar-napht-H), $12.81(\mathrm{~s}, 1 \mathrm{H}$, $\mathrm{NH}) .{ }^{13} \mathrm{C} N M R\left(100 \mathrm{MHz}, \mathrm{CDCl}_{3}, \mathrm{ppm}\right): \delta=$ $13.86,20.02,22.18,29.34,30.63,39.99$, $125.09,128.16,128.35,129.17,129.52$, $130.25,130.89,131.58,132.43,134.91$, $141.65,143.34,143.76,188.96,189.04$. ESI$\mathrm{MS}(+)\left[\mathrm{M}^{+}\right]: \quad \mathrm{m} / \mathrm{z}=\mathrm{C}_{21} \mathrm{H}_{20} \mathrm{BrN}_{3} \mathrm{O}_{2}$ Found : 426,3064; Calc. : 426,8538. IR (ATR) Umax $\left(\mathrm{cm}^{-1}\right)$ 2920, 2854, $1695(\mathrm{C}=0), 1653(\mathrm{C}=0), 1608$, $1575,1435,1384,1352,1303,1269,1226$, 1182, 1093, 1033, 995, 958, 918, 823, 779, 744,691 .

\section{3-(1,3,5-Trimethyl-4-pyrazolyl)-4-bromo-N- butyl-1,8-naphthalimide (5)}

Naphthalimide derivative compound (1) $(0.2 \mathrm{~g}$, $0.43 \mathrm{mmol}), \mathbf{1}, 3,5$-dimethyl-4-pyrazoleboronic acid pinacol ester $(0.9 \mathrm{~g}, 1.3 \mathrm{mmol})$, tetrakis(triphenylphosphine)palladium(0) (0.049 $\mathrm{g}, 0.043 \mathrm{mmol})$, potassium carbonate $(0.59 \mathrm{~g}$, $4.3 \mathrm{mmol})$, catalyst ratio of tris (dibenzylideneacetone)dipalladium(0), THF (30 $\mathrm{mL})$, aqueous $(10 \mathrm{~mL})$ stirred for 5 hours at room temperature. When TLC control was performed, it was observed that the product was not photochromic. After heating for 3 hours at $65{ }^{\circ} \mathrm{C}$, TLC was checked. $10 \%$ sodium bicarbonate solution was added. The organic fraction was dried with sodium sulphate. The organic fraction was then evaporated. The residual raw product was purified via column chromatography eluting over ethyl acetate-nhexane (5-20\%). ${ }^{1} \mathrm{H}$ NMR was taken and it was found to bind $1 \mathrm{~mol}$. 5 Pale coloured yellow solid 0.12 g, 63\%, m.p.: $157-160{ }^{\circ} \mathrm{C} .{ }^{1} \mathrm{H}$ NMR (400 $\left.\mathrm{MHz}, \mathrm{CDCl}_{3}, \mathrm{ppm}\right): \delta 0.83\left(\mathrm{t}, 3 \mathrm{H},-\mathrm{CH}_{2} \mathbf{C H}_{3}\right)$, 1.29-1.37 (m, 2H, $\left.-\mathbf{C H}_{2} \mathrm{CH}_{3}\right), 1.51-1.64(\mathrm{~m}, 2 \mathrm{H}$, $\left.-\mathrm{NCH}_{2} \mathbf{C H}_{2}-\right), 2.02\left(\mathrm{~s}, 3 \mathrm{H},-\mathrm{CH}_{3}\right.$, pyrazole), 2.34 $\left(\mathrm{s}, 3 \mathrm{H},-\mathrm{CH}_{3}\right.$, pyrazole), 3.50(s, 3H, $-\mathrm{NCH}_{3}$, pyrazole), $4.01\left(\mathrm{t}, 2 \mathrm{H},-\mathrm{NCH}_{2}-\right), 7.00-8.50(\mathrm{~m}$, $4 \mathrm{H}$, Ar-napht-H). ${ }^{13} \mathrm{C}$ NMR $\left(100 \mathrm{MHz} \mathrm{CDCl}_{3}\right.$, ppm): $\delta=13.67,14.32,20.07,23.13,29.46$, $30.25,40.18,125.10,125.33,128.24,128.61$, $129.30,129.73,130.15,130.47,131.51$, 131.83, 134.16, 134.38, 143.55, 189.03, 189.13. ESI-MS(+) $\left[\mathrm{M}^{+}\right]: \mathrm{m} / \mathrm{z}=\mathrm{C}_{22} \mathrm{H}_{22} \mathrm{BrN}_{3} \mathrm{O}_{2}$ Found : 440,3330; Calc. : 440,0051. IR (ATR) $U_{\max }\left(\mathrm{cm}^{-1}\right) \quad 2925,2884,1701 \quad(\mathrm{C}=0), 1667$ $(C=0), 1613,1556,1438,1377,1355,1315$, $1267,1226,1145,1078,1041,996,947,854$, $785,746,698,634$.
3,4-Bis(3,5-dimethyl-4-pyrazolyl)-N-butyl-1,8naphthalimide (6)

3,5-dimethyl-4-pyrazolyl naphthalimide derivative (4) $(0.09 \mathrm{~g}, 0.21 \mathrm{mmol}), 3,5-$ dimethyl-4-pyrazoleboronic acid pinacol ester $(0.094 \mathrm{~g}), 0.42 \mathrm{mmol})$, tetrakis (triphenylphosphine)-palladium(0) (0.024 g, $0.021 \mathrm{mmol})$, potassium carbonate $(0.29 \mathrm{~g}, 2.1$ $\mathrm{mmol})$, catalyst ratio of tris(dibenzylideneacetone)dipalladium(0), THF (30 $\mathrm{mL})$, water $(10 \mathrm{~mL})$ stirred for 5 hours at room temperature. TLC control showed that the product was formed. After heating at $65^{\circ} \mathrm{C}$ for 3 hours, the reaction mixture product was terminated by checking with TLC. $10 \%$ sodium bicarbonate solution was added. Extraction was performed over ethyl acetate-n-hexane. The organic fraction was dried with sodium sulphate. The organic fraction was then evaporated in vacuo. The residual raw product was purified via column chromatography, with an ethyl acetaten-hexane (5-20\%) mixture. ${ }^{1} \mathrm{H}$ NMR of the product was taken. 6 Yellow-orange solid $0.03 \mathrm{~g}$, $33 \%$, m.p.: $160-162{ }^{\circ} \mathrm{C} .{ }^{1} \mathrm{H}$ NMR (400 MHz, $\left.\mathrm{CDCl}_{3}, \mathrm{ppm}\right): \delta 0.81\left(\mathrm{t}, 3 \mathrm{H},-\mathrm{CH}_{2} \mathbf{C H}_{3}\right), 1.30-$ $1.38\left(\mathrm{~m}, 2 \mathrm{H},-\mathbf{C H}_{2} \mathrm{CH}_{3}\right), 1.55-1.60(\mathrm{~m}, 2 \mathrm{H}$, $\left.\mathrm{NCH}_{2} \mathbf{C H}_{2}-\right), 1.99\left(\mathrm{~s}, 6 \mathrm{H},-\mathrm{CH}_{3}\right.$, pyrazole), 2.12 $\left(\mathrm{s}, 6 \mathrm{H},-\mathrm{CH}_{3}\right.$, pyrazole), $4.06\left(\mathrm{t}, 2 \mathrm{H},-\mathrm{NCH}_{2}-\right)$, 7.01-8.80 (m, 4H, Ar-napht-H), 12.89 (s, $1 \mathrm{H}$, $\mathrm{NH}) .{ }^{13} \mathrm{C}$ NMR $\left(100 \mathrm{MHz}, \mathrm{CDCl}_{3}, \mathrm{ppm}\right): \delta=$ $13.84,14.05,20.03,20.32,29.06,29.41$, $30.08,40.49,121.40,125.14,125.62,128.10$, $128.46,129.21,129.53,130.18,130.65$, 131.73, 132.28, 132.84, 134.07, 134.35, 141.19, 143.57, 189.04, 189.24. ESI-MS (+) positive ion mode $\left[\mathrm{M}^{+}\right]: \mathrm{m} / \mathrm{z}=\mathrm{C}_{26} \mathrm{H}_{27} \mathrm{~N}_{5} \mathrm{O}_{2}$ Found : 441,5249; Calculated : 441,5629. IR (ATR) $U_{\max }\left(\mathrm{cm}^{-1}\right) 3051,2954,2924,2856,1697$ $(\mathrm{C}=0), 1649(\mathrm{C}=0), 1622,1583,1492,1444$, $1390,1336,1309,1261,1224,1188,1101$, 1074, 1039, 981, 921, 883, 850, 825, 756, 688, 624.

\section{3,4-Bis(1,3,5-Trimethyl-4-pyrazolyl)-N-butyl- 1,8-Naphthalimide (7) \\ 3-(1,3,5-Trimethyl-4-pyrazolyl)-4-bromo-1,8-} naphthalimide (5) $(0.12 \mathrm{~g}, 0.27 \mathrm{mmol}), \mathbf{1 , 3 , 5 -}$ dimethyl-4-pyrazoleboronic acid pinacol ester $(0.12 \mathrm{~g}, 0.54 \mathrm{mmol})$, tetrakis(triphenylphosphine)palladium(0) (0.031 g, $0.027 \mathrm{mmol})$, potassium carbonate $(0.37 \mathrm{~g}, 2.7$ $\mathrm{mmol}$ ), catalyst ratio of tris(dibenzylideneacetone)dipalladium $(0)$, THF $(30 \mathrm{~mL})$, water $(10$ $\mathrm{mL}$ ) was stirred for 5 hours at room temperature. When TLC control was performed, it was observed that the product was not photochromic. After heating at $65^{\circ} \mathrm{C}$ for 3 hours, the reaction mixture product was terminated by checking with TLC. $10 \%$ sodium bicarbonate solution was added. Extraction was performed over ethyl acetate-n-hexane. The 
organic fraction was dried with sodium sulfate. The organic fraction was then evaporated in vacuo. The residual raw product was purified via column chromatography, with an ethyl acetaten-hexane (5-20\%) mixture. 7 Light brown coloured solid 0.05 g, 42\%, m.p.: $169-171{ }^{\circ} \mathrm{C}$.
${ }^{1} \mathrm{H}$ NMR (400 MHz, $\left.\mathrm{CDCl}_{3}, \mathrm{ppm}\right): \delta 0.82(\mathrm{t}, 3 \mathrm{H},-$ $\left.\mathrm{CH}_{2} \mathbf{C H}_{3}\right), 1.28-1.36\left(\mathrm{~m}, 2 \mathrm{H},-\mathbf{C H}_{2} \mathrm{CH}_{3}\right), 1.50-$ $1.62\left(\mathrm{~m}, 2 \mathrm{H},-\mathrm{NCH}_{2} \mathbf{C H}_{2}-\right), 2.06\left(\mathrm{~s}, 6 \mathrm{H},-\mathrm{CH}_{3}\right.$, pyrazole), $2.33\left(\mathrm{~s}, 6 \mathrm{H},-\mathrm{CH}_{3}\right.$, pyrazole), 3.57(s, $6 \mathrm{H},-\mathrm{NCH}_{3}$, pyrazole), $4.09\left(\mathrm{t}, 2 \mathrm{H},-\mathbf{N C H}_{2}^{-}\right)$, 7.20-8.60 (m, 4H, Ar-napht-H).

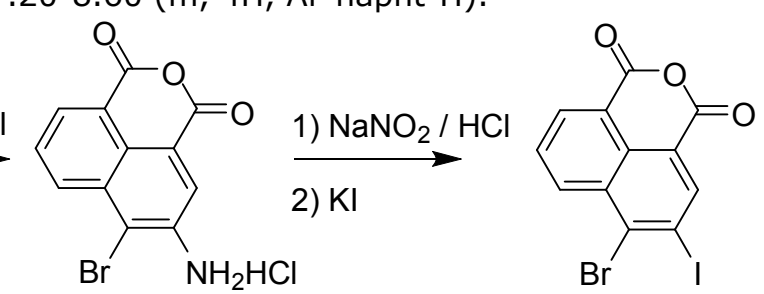

$\mathrm{Br}$<smiles>O=C1OC(=O)c2ccc([N+](=O)[O-])c3c(Br)ccc1c23</smiles>

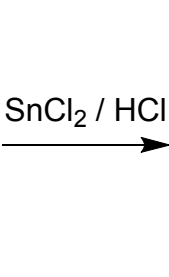<smiles>CCCCN1C(=O)c2cccc3c(Br)c(I)cc(c23)C1=O</smiles>

1<smiles>CCCCN1C(=O)c2cccc3c(Br)c(I)cc(c23)C1=O</smiles><smiles>[R]n1nc(C)c(B(C)OCC)c1C</smiles>

1

$$
2 \mathbf{R}=\mathbf{H}
$$

$4 \mathbf{R}=\mathbf{H}$

$$
3 \mathbf{R}=\mathrm{CH}_{3}
$$

$5 \quad \mathrm{R}=\mathrm{CH}_{3}$
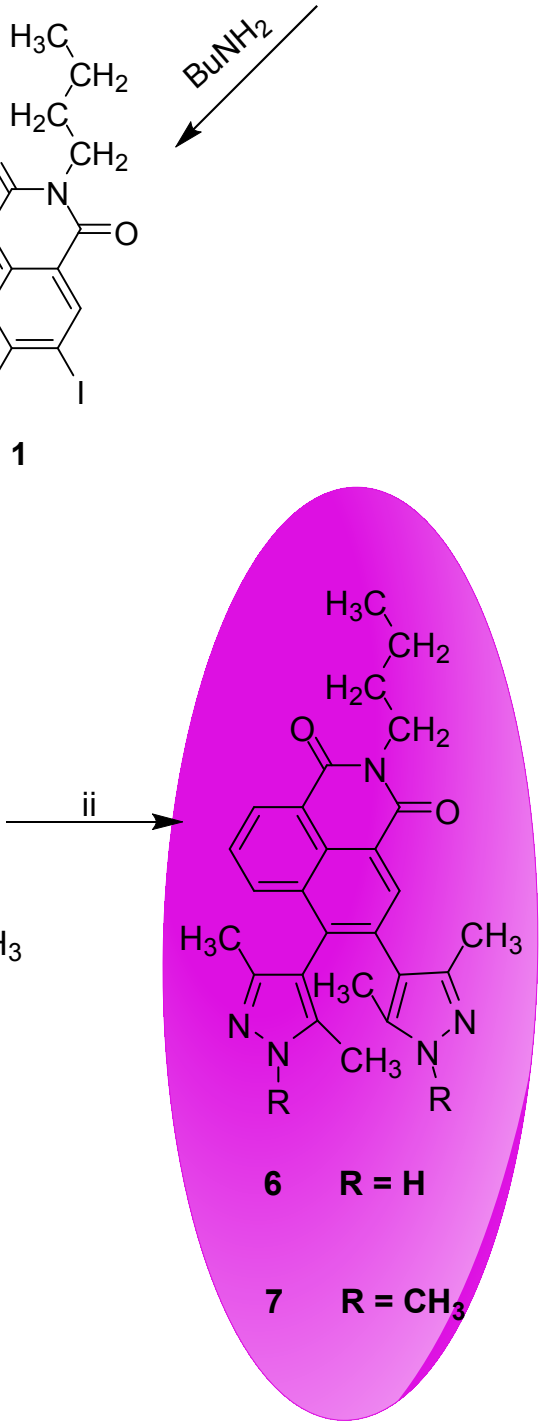

Figure 1. Syntheses of 6 and 7.

Conditions: i) $\mathrm{K}_{2} \mathrm{CO}_{3} / \mathrm{Pd}\left(\mathrm{PPh}_{3}\right)_{4}, \mathrm{THF}_{1} \mathrm{H}_{2} \mathrm{O}, 4$ hours at room temperature and 3 hours heating at $65{ }^{\circ} \mathrm{C}$; ii) Excess of 2 or $3 / \mathrm{K}_{2} \mathrm{CO}_{3} / \mathrm{Pd}\left(\mathrm{PPh}_{3}\right)_{4}, \mathrm{THF}, \mathrm{H}_{2} \mathrm{O}, 4$ hours at room temperature and 3 hours of heating at 65 ${ }^{\circ} \mathrm{C}$.

${ }^{13} \mathrm{C}$ NMR $\left(100 \mathrm{MHz}, \mathrm{CDCl}_{3}, \mathrm{ppm}\right): \delta=13.75$, $14.21,20.46,23.06,29.17,29.74,30.38$, $32.10,40.24,40.69,118.81,119.09,121.77$, $122.15,126.36,127.67,128.54,128.73$, $129.39,129.71,130.22,130.48,131.32$,
$131.55,135.28,141.34,164.37,166.82$. ESIMS (+) positive ion mode $\left[\mathrm{M}^{+}\right]$: $\mathrm{m} / \mathrm{z}=$ $\mathrm{C}_{28} \mathrm{H}_{31} \mathrm{~N}_{5} \mathrm{O}_{2}$ Found : 469,2478; Calculated : 469,0253. IR (ATR) Umax $\left(\mathrm{cm}^{-1}\right)$ 3053, 3026, 2954, 2922, 2854, $1697(\mathrm{C}=\mathrm{O}), 1649(\mathrm{C}=\mathrm{O})$, 
$1620,1585,1490,1440,1390,1336,1286$, $1261,1222,1188,1097,1076,1029,983,921$, $883,848,754,679,623$.

\section{RESULTS AND DISCUSSION}

Previously, a study involving naphthalimide derivative compound 1 and pyrazole group with arylboronic acid ester was prepared in the literature by a multi-step reaction method (24).

The Suzuki cross-linking reaction forms a new C$C$ bond using a palladium catalyst and base. These new $\mathrm{C}-\mathrm{C}$ bond formation reactions may find application in the development of organic, polymeric and inorganic materials in many industrial fields, particularly in the fields of electrical-electronics, optical properties.

Naphthalimide compound containing 3,5dimethyl-4-pyrazolyl group 6, naphthalimide compound containing 1,3,5-trimethyl-4pyrazolyl group 7 were synthesised by a twostep Suzuki coupling reaction of naphthalimide derivative compound 1 and 3,5-dimethyl-4(4,4,5,5-tetramethyl-1,3,2-dioxaborolan-2-yl)$1 \mathrm{H}$-pyrazole and 1,3,5-dimethyl-4pyrazoleboronic acid pinacol ester in medium yield (Figure 1).

In the reaction of naphthalimide derivative compound 1 between both 3,5-dimethyl-4(4,4,5,5-tetramethyl-1,3,2-dioxaborolan-2-yl)$1 \mathrm{H}$-pyrazole and 1,3,5-dimethyl-4pyrazoleboronic acid pinacol ester (pinacol ester of arylboronic acid) failed to give new compound 6 and compound 7 when taken as two moles. Instead of, the new intermediate product 4 and 5 were obtained light brown coloured solid and pale yellow coloured solid, respectively. Although the one-step reaction is repeated with excessive amounts of 3,5-dimethyl-4-(4,4,5,5tetramethyl-1,3,2dioxaborolan-2-yl)-1H-

pyrazole 2 and 1,3,5-dimethyl-4-pyrazoleboronic acid pinacol ester 3 in addition to more effective reaction conditions, the desired product 6 and product 7 were not isolated and some byproducts which could not be isolated by TLC were observed. However, when the pure intermediate new product 3-(3,5-dimethyl-4pyrazolyl)-4-bromo-N-butyl-1,8-naphthalimide 4 and 3-(1,3,5-trimethyl-4-pyrazolyl)-4-bromo-Nbutyl-1,8-naphthalimide 5 were treated with an extreme quantity of 3,5-dimethyl-4-(4,4,5,5tetramethyl-1,3,2-dioxaborolan-2-yl)-1H-

pyrazole 2 and 1,3,5-dimethyl-4-pyrazoleboronic acid pinacol ester 3 , the expected product 6 and product 7 were achieved in $33 \%$ yield and $42 \%$ yield as a yellow orange coloured solid and light brown coloured solid, respectively.
Irradiation of pyrazole groups bearing N-butyl1,8-naphthalimide, naphthalimide compound containing 3,5-dimethyl-4-pyrazolyl group 6, naphthalimide compound containing 1,3,5dimethyl-4-pyrazolyl group $\mathbf{7}$ in ethyl acetate via $365 \mathrm{~nm}$ light did not cause colour change, due to the formation close form. The possible coloured form (in photostationary state, pss) was expected to return to the first colourless or pale yellow coloured naphthalimide compound containing 3,5-dimethyl-4-pyrazolyl group 6, naphthalimide compound containing 1,3,5dimethyl-4-pyrazolyl group $\mathbf{7}$ solution when exposed to visible light $(530 \mathrm{~nm})$.

When examined for fluorescence, these compounds, namely naphthalimide compound containing 3,5-dimethyl-4-pyrazolyl group 6, naphthalimide compound containing 1,3,5dimethyl-4-pyrazolyl group $\mathbf{7}$ exhibited good fluorescence.

Synthesized naphthalimide compound containing 3,5-dimethyl-4-pyrazolyl group 6 and naphthalimide compound containing 1,3,5dimethyl-4-pyrazolyl group 7 were not photochromic. Otherwise, these prepared naphthalimide compound containing 3,5dimethyl-4-pyrazolyl group 6 and naphthalimide compound containing 1,3,5-dimethyl-4-pyrazolyl group $\mathbf{7}$ exhibited a good level of fluorescent properties.

Irradiation via $365 \mathrm{~nm}$ light showed no colour change and no spectral change. The reason why naphthalimide compound containing 3,5dimethyl-4-pyrazolyl group 6 and naphthalimide compound containing 1,3,5-dimethyl-4-pyrazolyl group 7 does not exhibit any photochromism is unclear at this stage. However, it can be said that the methyl groups in these carbon groups form a steric hindrance on the pyrazoles at the 3-position and the naphthalimide group at the 3position with hydrogen atoms. In the cyclisation step during photoreaction, it is believed that the methyl groups coincide with the hydrogen of the naphthalimide ring as in Figure 2. 


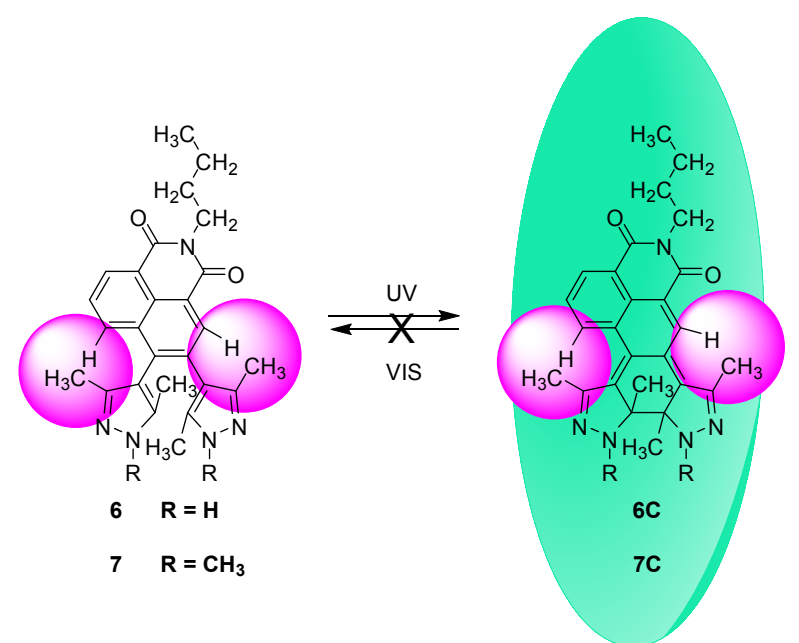

Figure 2. Possible photoreaction of nonphotochromic 6C and 7C.

Therefore, it causes deviation from the planarity required for cyclization. Although compounds naphthalimide compound containing 3,5dimethyl-4-pyrazolyl group 6 and naphthalimide compound containing 1,3,5-dimethyl-4-pyrazolyl group $\mathbf{7}$ are not photochromic compounds, 6 and $\mathbf{7}$ exhibited fluorescence properties (Figures 3 and 4$)$.

\section{Photochromic and Fluorescent Properties}

Naphthalimide compound containing 3,5dimethyl-4-pyrazolyl group $\mathbf{6}$, naphthalimide compound containing 1,3,5-dimethyl-4-pyrazolyl group 7 solutions had no observed absorption band in the visible range and were pale yellow or colourless. After irradiation with $365 \mathrm{~nm}$ ultraviolet light, compound $\mathbf{6}$ and compound 7 solutions were expected to return to the coloured form with an increase in new peaks in the visible region. This would show an expanded $\pi$ system on the photochromic reaction.

The reversible photoreaction of naphthalimide compound containing 3,5-dimethyl-4-pyrazolyl group 6, naphthalimide compound containing 1,3,5-dimethyl-4-pyrazolyl group $\mathbf{7}$ in the solutions were carried out at $365 \mathrm{~nm}$ and 530 $\mathrm{nm}$ various light wavelengths. It was thought that when irradiated in solutions compound 6 and compound $\mathbf{7}$ with $365 \mathrm{~nm}$ ultraviolet light, from colourless or pale yellow state to coloured state, when they returned (visible light $530 \mathrm{~nm}$ ), it would be transformed into coloured form due to the formation of closed form C-forms.

In general, for naphthalimide compound containing 3,5-dimethyl-4-pyrazolyl group 6 and naphthalimide compound containing 1,3,5dimethyl-4-pyrazolyl group 7 compounds are not in the same plane due to steric hindrances between the methyl groups of the two pyrazolyl groups and the naphthalimide hydrogens.
However, they always maintain their parallel and antiparallel shape. Thus, the observed characteristic absorption peaks of the naphthalimide moieties result in poor conjugation between the pyrazolyl ring groups and the naphthalimide moiety. Such a situation prevents the photochromicity from being observed.

The solvent effects on the open forms of compounds naphthalimide compound containing 3,5-dimethyl-4-pyrazolyl group 6 and naphthalimide compound containing 1,3,5dimethyl-4-pyrazolyl group $\mathbf{7}$ have been investigated in various solvents. The polarity of the solvent showed a shift to long wavelength in uncoloured forms. Quantum yields could not be calculated because the new compounds $\mathbf{6}$ and $\mathbf{7}$ synthesized were not photochromic.

Electrochemical behavior of both the ring-open and ring-closed forms of photochromic fluorescence compounds can be performed such as absorbance and emission properties, recording-deletion, and hologram acquisition. The difference in fluorescence emission between these reversible transformations is remarkable because it is easy to see. Here, the naphthalimide structure serves as a very important core for fluorescence emission.

It can be mentioned that pyrazole groups containing naphthalimide ring show fluorescent photo-transfer property. Naphthalimide compound containing 3,5-dimethyl-4-pyrazolyl group 6 and naphthalimide compound containing 1,3,5-dimethyl-4-pyrazolyl group 7 showed maximum fluorescence emission at $505 \mathrm{~nm}$ and $500 \mathrm{~nm}$, respectively, when light stimulation was performed at a wavelength of $400 \mathrm{~nm}$.

In addition, emission intensity-wavelength graph was obtained by taking emission measurements against wavelength in compound naphthalimide compound containing 3,5-dimethyl-4-pyrazolyl group 6 and naphthalimide compound containing 1,3,5-dimethyl-4-pyrazolyl group 7 in non-polar n-hexane and polar acetone solvents. While the maximum wavelengths in non-polar n-hexane solvent were around $460 \mathrm{~nm}$, the maximum wavelength in polar acetone solution gave emission around $520 \mathrm{~nm}$ and $510 \mathrm{~nm}$. As solvent polarity increases, the maximum emission intensity shifts to a longer wavelength. In the more polar acetone solvent $50 \mathrm{~nm}$ and $60 \mathrm{~nm}$ give longer wavelength emission intensity (Figures 3 and 4). 


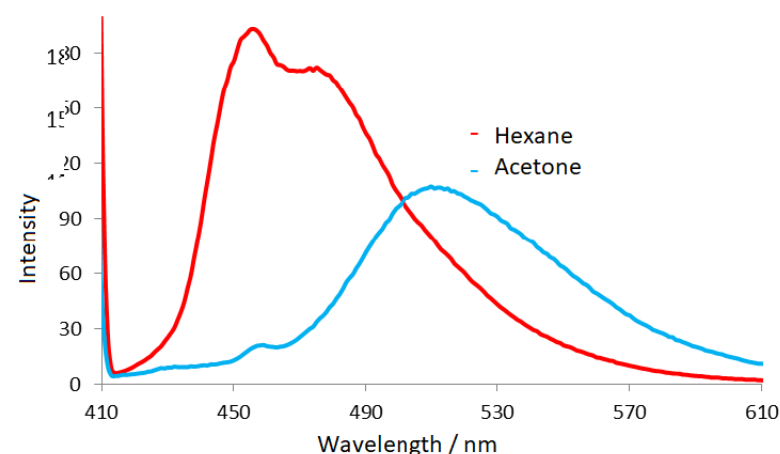

Figure 3. Emission spectra of compound 6 in $\mathbf{n -}$ hexane and acetone $\left(1 \times 10^{-5}\right),\left(\lambda_{\text {ex }} 400 \mathrm{~nm}\right)$.

It can be seen from the graphs that the solvent polarity for compounds $\mathbf{6}$ and $\mathbf{7}$ are an important factor in shifting the luminescent wavelength to the long wavelength between the non-polar solvent and the polar solvent. When the polarity of the solvent increases, the emission intensity gives a peak at a longer wavelength. The fluorescence colour of compounds $\mathbf{6}$ and $\mathbf{7}$ can be directly modulated by the naked eye by adjusting the polarity of the solvent.

Naphthalimide compound containing 3,5dimethyl-4-pyrazolyl group 6 and naphthalimide compound containing 1,3,5-dimethyl-4-pyrazolyl group $\mathbf{7}$ the emission spectrum of the compounds by the excitation intensity and wavelength at 400

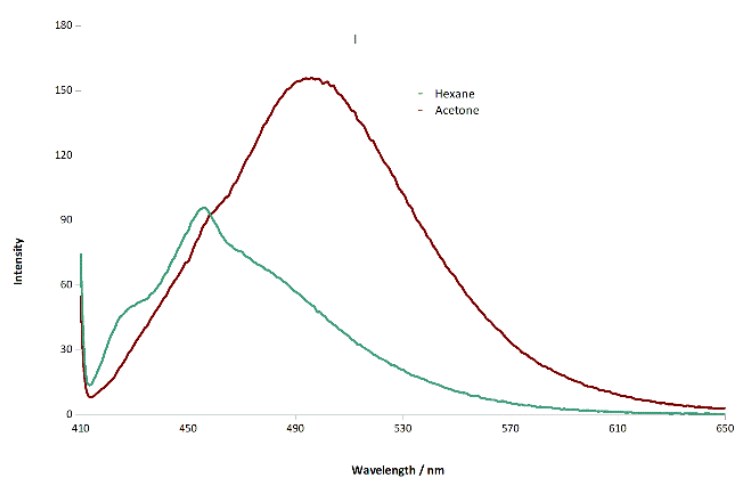

Figure 4. Emission spectra of compound $\mathbf{7}$ in $\mathbf{n}-$ hexane and acetone $\left(1 \times 10^{-5}\right),\left(\lambda_{\text {ex }} 400 \mathrm{~nm}\right)$.

$\mathrm{nm}$ in the ethyl acetate solvent at a concentration of $1 \times 10^{-5} \mathrm{M}$ is given in Figure 5 . At the same concentration maximum naphthalimide compound containing 1,3,5-dimethyl-4-pyrazolyl group $\mathbf{7}$ at higher wavelengths gives higher emission intensity while naphthalimide compound containing 3,5-dimethyl-4-pyrazolyl group 6 gave a lower emission intensity.

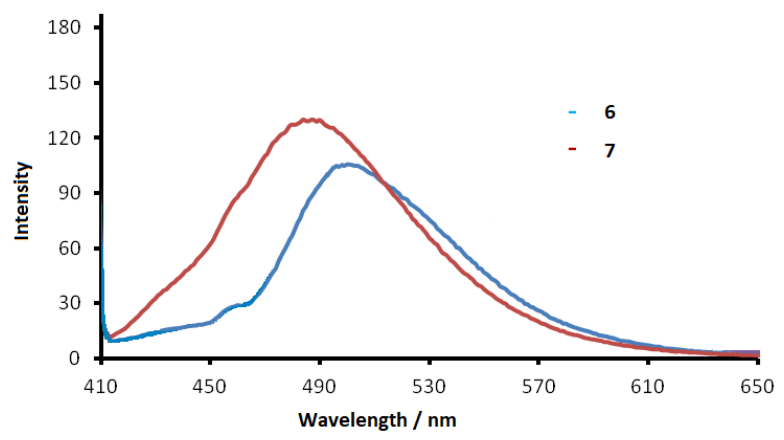

Figure 5. Emission spectrum generated by excitation of different compounds $\mathbf{6}$ and $\mathbf{7}$ at $400 \mathrm{~nm}$ wavelength in ethyl acetate $\left(1 \times 10^{-5} \mathrm{M}\right)$.

Compound 7 gives an emission intensity at 480 $\mathrm{nm}$, while compound $\mathbf{6}$ gives an emission intensity at $510 \mathrm{~nm}$ at the same concentration. It is observed that the emission spectrum of compound $\mathbf{6}$ shifts to a wavelength longer than $30 \mathrm{~nm}$. In addition, compounds $\mathbf{6}$ emit at longer wavelengths and lower intensity, while compound $\mathbf{7}$ emit at shorter wavelengths and higher intensity.

\section{CONCLUSIONS}

Synthesis of naphthalimide derivative compound 1 from 4-bromo-1,8-naphthalic anhydride starting material was prepared according to literature in several steps. Naphthalimide compound containing 3,5-dimethyl-4-pyrazolyl group 6 and naphthalimide compound containing 1,3,5-dimethyl-4-pyrazolyl group 7 derivatives, naphthalimide derivative compound $\mathbf{1}$ and 3,5dimethyl-4-pyrazoleboronic acid pinacol ester 2, 1,3,5-dimethyl-4-pyrazoleboronic acid pinacol ester 3 were synthesized from the Suzuki coupling reaction of boronic acid pinacol ester.

The photochromic and fluorescent properties of compounds $\mathbf{6}$ and $\mathbf{7}$ were examined. None of the N-butyl-1,8-naphthalimides containing both pyrazole and $\mathrm{N}$-methyl pyrazole groups exhibited photochromic properties.

The polar and non-polar solvent factor on the fluorescence properties of compounds $\mathbf{6}$ and $\mathbf{7}$ were examined. Increasing solvent polarity was observed to shift fluorescence emissions to longer wavelengths.

\section{ACKNOWLEDGEMENTS}

The authors would like to thank Duzce University Research Fund (Project No.: BAP 2012.05.HD.053 and BAP 2012.05.03.097) and Scientific and Technical Research Council of Turkey (TUBİTAK) (Project No.: 111T490) for their financial support. 


\section{REFERENCES}

1. Cipolloni M, Ortica F, Bougdid L, Moustrou C, Mazzucato $U$ and Favaro G. New Thermally Irreversible and Fluorescent Photochromic Diarylethenes. J. Phys. Chem. A. 2008; 112:4765-71.

2. Yamaguchi $H$, Matsuda $\mathrm{K}$ and Irie $\mathrm{M}$. ExcitedState Behavior of a Fluorescent and Photochromic Diarylethene on Silver Nano particles. J. Phys. Chem. C. 2007; 111: 385362.

3. Liu HH and Chen Y. The Photochromism and Fluorescence of Diarylethenes with a Imidazole Bridge Unit: A Strategy for the Design of Turnon Fluorescent Diarylethene System. J. Phys. Chem. A. 2009; 113:5550-53.

4. Gundogdu L, Kose M, Takeuchi S, Yokoyama $Y$, Orhan E. Synthesis, photochromic and fluorescence properties of new bithiazolecontaining diarylethenes as cation sensors. Journal of Luminescence. 2018; 203:568-75.

5. Orhan E, Köse M, Yazan T. The synthesis of new 3,4-(bisaryl)-1,8-naphthalimide and 2,3(bisaryl)-7HH-benzimidazo[2,1-

a]benzo[d]isoquinolin-7-one compounds and an investigation of their photochromic properties. Turk J Chem. 2018; 42:1086-94.

6. Orhan E, Gundogdu L, Kose M, Yokoyama Y. Synthesis and photochromic properties of 4,5bisaryl-3(2H)-pyridazinones. Journal of Photochemistry and Photobiology A: Chemistry. 2016; 314:164-70.

7. Yagi K, Soong CF and Irie M. Synthesis of Fluorescent Diarylethenes Having a 2,4,5Triphenylimidazole Chromophore. J. Org. Chem. 2001; 66:5419-23.

8. Fukaminato T, Sasaki T, Kawai T, Tamai N and Irie $M$. Digital Photoswitching of Fluorescence Based on the Photochromism of Diarylethene Derivatives at a Single- Molecule Level. J. Am. Chem. Soc. 2004; 126(45):1484349.

9. Uchida $\mathrm{K}$, Nakamura $\mathrm{S}$, Irie $\mathrm{M}$. Photochromism of dinaphthylethene derivatives. Stability of the closed-ring forms. Res. Chem. Intermed. 1995; 21(8-9):861-76.

10. Milder MTW, Herek JL, Areephong J, Feringa $\mathrm{BL}$ and Browne WR. Tunable Aggregationand Luminescence of Bis(diarylethene)sexithiophenes. J. Phys. Chem. A. 2009; 113:7717-24.
11. Nakagawa T, Hasegawa $\mathrm{Y}$ and Kawai $\mathrm{T}$. Photoresponsive Europium(III) Complex Based on Photochromic Reaction. J. Phys. Chem. A. 2008; 112(23):5096-103.

12. Kose M, Orhan E, Suzuki K, Tutar A, Ünlü CS, Yokoyama Y. Preparation and photochromic properties of 2,3-bisarylbenz[f]indenones. Journal of Photochemistry and Photobiology A: Chemistry. 2013; 257:50-53.

13. Kose M, Orhan E. Comparison of photochromic properties and thermal stabilities of fulgide, fulgimide, and benzimidazole[1,2a]pyrrolidine-2-one derivatives. Turk J Chem. 2009; 33:579-88.

14. Orhan E. Synthesis of Novel Diarylethenes Bearing Naphthalimide Moiety and Photochromic Fluorescence Behaviors. Journal of the Turkish Chemical Society, Section A: Chemistry. 2017; 4(2):501-16.

15. Tsujioka T, Irie M. Electrical functions of photochromic molecules. Journal of Photochemistry and Photobiology C: Photochemistry Reviews. 2010; 11:1-14.

16. Irie $M$. Diarylethenes for Memories and Switches. Chem. Rev. 2000; 100:1685-716.

17. Kose M, Orhan E, Buyukgungor O. Synthesis of novel photochromic methyl cyanoacetatecondensed fulgide derivatives. Journal of Photochemistry and Photobiology A: Chemistry. 2007; 188:358-63.

18. Kose M, Orhan E. Studies on photochromic benzimidazol[1,2a]pyrrolidin-2-ones from the condensation of 2-methyl-3benzothienylethylidene-(isopropylidene)succinic anhydride with 1,2-diaminobenzenes. Journal of Photochemistry and Photobiology A: Chemistry. $2006 ; 177: 170-76$.

19. Lin Q, Xiao S, Li R, Tan R, Wang S, Zhang R. Intermolecular hydrogen bonding- assisted high contrast fluorescent switch in the solid state. Dyes and Pigments. 2015; 114:33-39.

20. Kanazawa R, Nakashima $\mathrm{T}$ and Kawai $\mathrm{T}$. Photophysical Properties of a Terarylene Photoswitch with a Donor-Acceptor Conjugated Bridging Unit. J. Phys. Chem. A. 2017; 121(8):1638-46.

21. Shirinian ZV, Lonshakov DV, Kachala VV, Zavarzin IV, Shimkin AA, Lvov AG, Krayushkin MM. Regio- and chemoselective bromination of 2,3- diarylcyclopent-2-en-1-ones. J. Org. Chem. 2012; 77:8112-23. 
22. Jiang GY, Wang S, Yuan WF, Zhao Z, Duan AJ, $X u$ CM, et al. Photo- and protondualresponsive fluorescence switch based on a bisthienylethene-bridged naphthalimide dimer and its application in security data storage. Eur J Org Chem. 2007; 2064-67.

23. Pu S, Li H, Liu G, Liu W, Cui S, Fan C. Sythesis and the effects of substitution upon photochromic diarylethenes bearing an isoxazole moiety. Tetrahedron. 2011; 67: 1438-47.

24. Meng $X$, Zhu $W$, Zhang $Q$, Feng $Y$, Tan $W$ and Tian $\mathrm{H}$. Novel Bisthienylethenes Containing Naphthalimide as the Center Ethene Bridge: Photochromism and Solvatochromism for Combined NOR and INHIBIT Logic Gates. J. Phys. Chem. B. 2008; 112:15636-45. 
